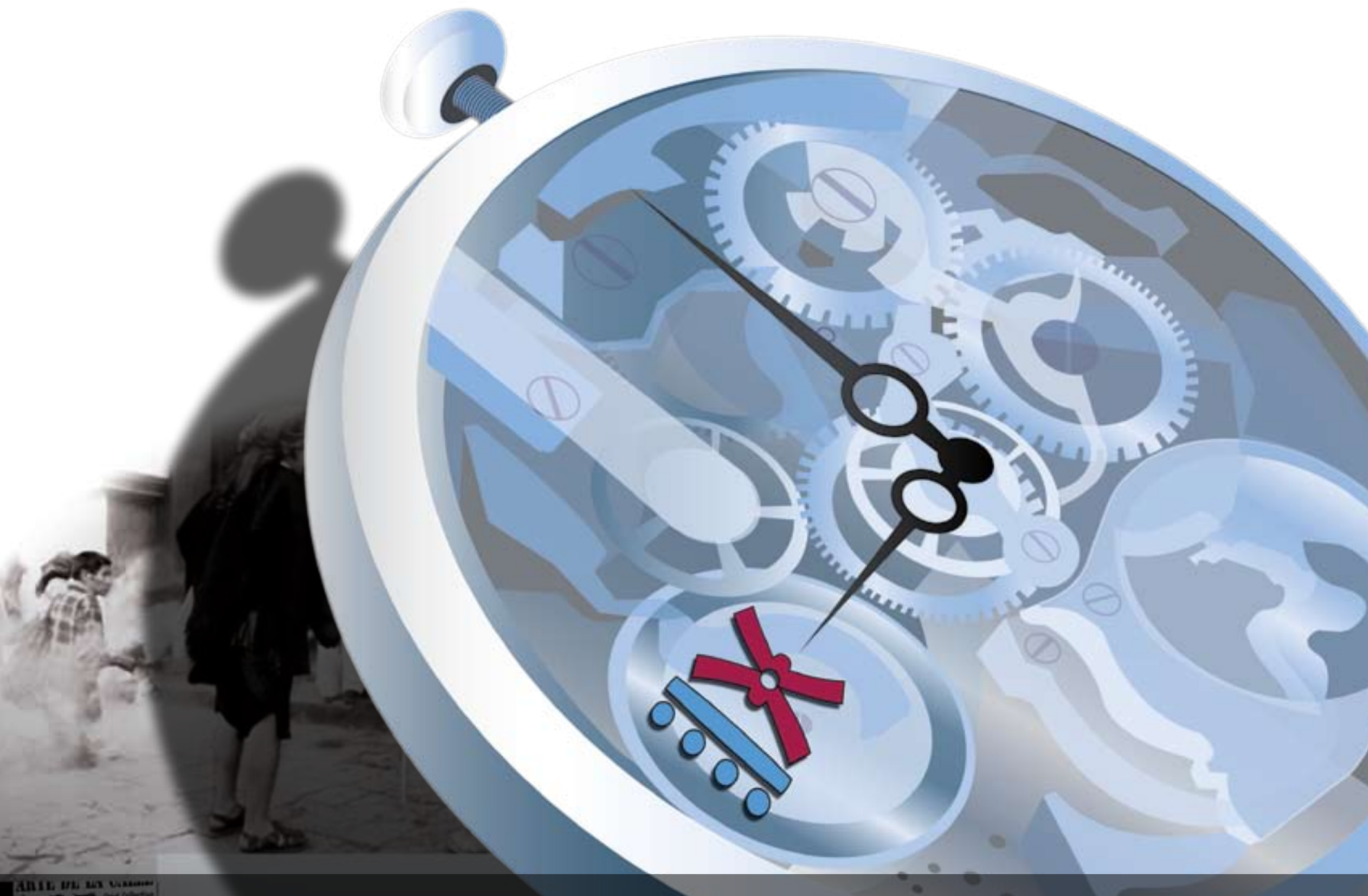

$9^{\circ}$ C O NG RESO 2. CENTROAMERICANO DE H IS TO R I A
ISSN 1409-469X

Fecha de recepción: 15 de mayo 2008 Fecha de aceptación: 30 de mayo 2008

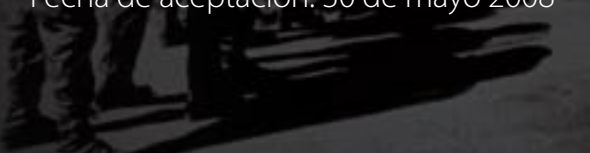

Textualidades extrañas y eclécticas; visiones atrevidas y excéntricas: mujeres guatemaltecas en la narrativa breve y el arte contemporáneo
Miembros del Consejo Editorial:

Dr. Ronny Viales, Dr. Juan José Marín

Editores Técnicos:

Allan Fonseca, Andrés Cruz, Gabriela Soto
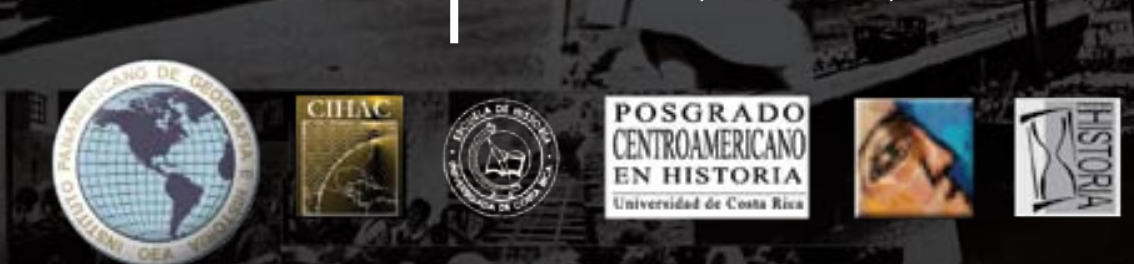
ON $9^{\circ}$ CONGRESO

:U CENTROAMERICANO

Universidad de costa Rice

Indexaciones: Repositorio de Revistas UCR, DIALNET, Latindex, REDALYC Directorio y recolector de recursos digitales del Ministerio de Cultura de España, Directory of Open Access Journals. Diálogos Revista Electrónica de Historia ISSN 1409-469X. Número especial 2008. Dirección web: http://historia.fcs.ucr.ac.cr/dialogos.htm

\section{Textualidades extrañas y eclécticas; visiones atrevidas y excéntricas: mujeres guatemaltecas en la narrativa breve y el arte contemporáneo}

Aida Toledo* 
Han pasado ya doce años desde que el gobierno y la guerrilla firmaran la paz en Guatemala. ${ }^{1}$ Los acuerdos de paz trajeron consigo una apertura cultural, desde la cual el arte y la literatura de Guatemala parecieron resurgir, en el sentido de emerger de forma mucho más pública. La postguerra trajo además de un ambiente más relajado políticamente hablando, apariciones de otras formas de arte y literatura. ${ }^{2}$ No queremos insinuar que durante la guerra de guerrillas, no se publicaran o escribieran libros y no hubiese habido exposiciones de arte, sobre todo en las galerías o espacios privados, que el arte guatemalteco estiló durante muchos años. Nos referimos a visualizar nuevas maneras de abordar el hecho artístico en las dos ramas de la cultura guatemalteca.

Al pasar estos doce años dentro de un periodo político llamado por la crítica la postguerra, ${ }^{3}$ en la literatura nacional se observó un fenómeno que le atañe a este trabajo específicamente, se abrieron espacios moderados de publicación para las minorías, tanto mujeres, indígenas como homosexuales alcanzaron con la postguerra derechos que no existían antes de la firma de la paz. Y aunque el país adolece de una agenda de publicaciones periódicas para estas minorías, se publicaron algunos libros como antologías donde se incluían a escritores que provenían de esos distintos espacios culturales y políticos. ${ }^{4}$ Dentro de este mar de nuevos escritores y aparecimiento de libros escritos por autores que no habían tenido acceso a los

1 Edelberto Torres-Rivas. Del autoritarismo a la paz. (Guatemala: FLACSO, 1998), 115.

2 Aida Toledo. "En el performance y la instalación: espacios imaginarios de artistas guatemaltecas", en Espejos que dejan ver. Mujeres en las artes visuales latinoamericanas. María Elvira Eriarte y Eliana Ortega Ed. Isis Internacional \#33. (Santiago de Chile, 2002), 146.

3 Lucrecia Méndez de Penedo. Introducción. Mujeres que cuentan. Lucrecia Méndez de Penedo y Aida Toledo Ed. Abrapalabra \#32. Universidad Rafael Landívar, 2000, 3.

$4 \quad$ Es el momento en que la Editorial Cultura empieza a ser dirigida por los grupos mayas. 
espacios de publicación gubernamental sobre todo, aparecieron libros escritos por mujeres trabajando un género, que tiene una larga tradición masculina en Guatemala, el del relato corto. ${ }^{5} \mathrm{Y}$ aunque estos textos no mostraran una marcada inclinación hacia lo canónico del género, fueron algunos de ellos publicados por el Ministerio de Cultura y por otras editoriales locales de carácter privado, para dar a conocer una obra que no había tenido oportunidades de publicación. Lo interesante de todo es que aparecieron estas textualidades publicadas no solo en forma de libro, sino en las revistas que se crearon durante este nuevo periodo político. Se estiló de parte de los grupos jóvenes, la fundación de editoriales pequeñas, que sacaban tirajes mínimos y donde no existía un proceso regular de distribución del libro. Algunas de estas editoriales ya no existen, se acabaron en la efervescencia del primer periodo de la postguerra.

Las escritoras que vamos a comentar aquí son, a los doce años de la firma de la paz, ejemplos claros de las búsquedas de una generación que intentó las formas de olvido de las que habla la antropología social, para terminar representando en sus relatos cortos y textos híbridos, ${ }^{6}$ las taras dejadas por el periodo de la guerra, y los estragos que a nivel de imaginarios ha causado la vida dentro de la postguerra.

Por su lado el arte desarrollado a partir de 1996 por las mujeres jóvenes de ese momento, donde se discutían inicialmente aspectos como la violencia política y de género, aunados a una polémica sobre estética y ética artísticas, ha continuado hasta el día de hoy con algunos de estos temas, pero su tratamiento ha ido desarrollándose hacia otras vertientes que se

$5 \quad$ En cuanto al tipo de género y registro, la narrativa desde esa perspectiva conservadora, estaba considerada como una escritura menos "femenina", es decir más propia de la mentalidad racional tradicionalmente atribuida al hombre. Ibid.

6 La construcción simbólica no es uniforme y las estrategias son muy variadas. La mayor parte tiende a la brevedad, pero así como se aprecian escasos fragmentos casi líricos, la mayor parte utiliza un lenguaje directo y a veces muy crudo. Ibid, 10. 
comentarán detenidamente en este trabajo. ${ }^{7}$

Deseamos probar a través de una revisión de la obra de algunas artistas y escritoras que han producido su obra durante el periodo de la postguerra, que sus articulaciones creativas han mantenido una agenda implícita que consiste en discutir y polemizar sobre aspectos fundamentales de la vida dentro de este periodo en Guatemala, dejando testimonios artísticos y discursivos, cuestionadores de las formas y maneras, en que el gobierno o mejor dicho los gobiernos, desde la firma de la paz, han conducido ese proceso, que ha afectado la vida política y civil, de una población que venía de sufrir los estragos de la guerra y que ha tenido que liar con sus efectos sicológicos, durante un periodo en donde no se ha cumplido con los acuerdos a cabalidad, para lograr el bienestar político y social de la población. ${ }^{8}$

La narrativa escrita por mujeres maneja en general tonalidades líricas, en cuanto a la condensación de los estados anímicos de los personajes y la tendencia del texto a lo autobiográfico. La brevedad por la que se particularizan estas textualidades hace que el relato oscile entre dos registros, uno poético en las formas de condensación de la imagen, y otro híbrido, porque no alcanza a articular, el ritmo progresivo de la narrativa canónica en el género del relato corto, especialmente escrito por los varones, sino prefiere intercambiar ritmos regresivos y escalonados, propios de la poesía postmoderna latinoamericana, que prefiere

$7 \quad$ La narradora guatemalteca ha sufrido un proceso que va de ser agredida a agresora. De la opresión y la represión, a la expresión de esta condición marginal. La revelación que el condicionamiento de género le ha sido impuesto con alevosía y ventaja frecuentemente ha implicado para muchos personajes de estos textos narrativos internalizar la propia agresión, y eventualmente, apoderarse del discurso masculino para fracturarlo. Ibid, 11.

8 Edelberto Torres-Rivas notaba en su libro de 1998 la importancia que tendría cumplir con los acuerdos de paz, ya que de ello dependía su éxito en términos históricos, y solo podrían cuantificarse en la medida en que se realizaran y se pudiera observar su efecto real en las relaciones sociales, lo cual no sucedió en su totalidad. Edelberto Torres-Rivas. Del autoritarismo a la paz, 159. 
la anécdota dentro del texto lírico, pero en donde no se encuentran los elementos mínimos de un texto narrativo por sí mismo. Las temáticas abordadas en la mayoría de estos textos nos remiten a aspectos históricos del espacio privado de las mujeres, no importando que los personajes sean masculinos.

Pensamos que el libro que funciona como el inicio de estas reflexiones de postguerra es el libro de Ana Maria Rodas, que se publica en 1996 en Artemis y Edinter, y con el que gana el Premio Hispanoamericano de Poesía de los Juegos Florales de Quetzaltenango en 1990, Mariana en la tigrera,${ }^{9}$ del cual existe una edición local de ese mismo año. Rodas trabaja alrededor de algunos de los temas centrales que se abordaron ampliamente en la narrativa de las nuevas narradoras de la postguerra. En "Monja de clausura"10 la voz narradora tiene una revelación cuando visita un convento en ruinas. Se entera a través de un artificio de comunicación entre el convento y el monasterio, de los amores de una monja durante la época colonial. El efecto emocional que le causa es tan fuerte que al final del texto decide atravesar el arco, que sustituye en este relato a ese espacio donde los tiempos -pasado y presente-, de la literatura y el cine se funden o se confunden. ${ }^{11}$ Este relato se intertextualiza con uno de los cuentos cortos de Mildred Hernández publicado en 1995 y titulado: "Los misterios del cuerpo y el alma", y en las revisitaciones del realismo-mágico, con los de Patricia Cortez de 1998. En

$9 \quad$ Ana María Rodas. Mariana en la tigrera. Guatemala: Artemis \& Edinter, 1996.

10 Ibid, 24-30.

11 De acuerdo a Guillermina Wallas en su análisis de los cuentos de Rodas, este cuento trabaja con la idea de lo erótico como satisfacción egocéntrica, donde el tema se resuelve en relación con el erotismo de la soledad, y la convivencia monógama que mata el deseo. "Mariana en la tigrera o la reversibilidad del nombrar". Desde la zona abierta: artículos críticos sobre la obra de Ana María Rodas. Aida Toledo Ed. (Guatemala: Editorial Palo de Hormigo, 2004), 195. 
el cuento de Hernández la mujer sufre una metamorfosis que la llevará de nuevo al pasado colonial del convento. En los dos casos hay una discusión en cuanto a tradición y modernidad, ya que la monja, paradigma del feminismo latinoamericano, representa esa tradición con la cual se identifican las autoras y hacia donde dirigen a sus personajes femeninos para cuestionar diferentes aspectos de su condición y papel social. En los dos casos es exitoso el retorno a esa tradición de donde proceden, porque tanto el personaje de Rodas logra mágicamente atravesar el arco, como el de Hernández sufre camaleónicamente la transformación. En uno y otro caso, las preocupaciones alrededor del tema del feminismo se suceden, las dos mujeres como producto de la modernidad acceden al amor con el confort de la época, pero la intensidad de esos encuentros cortesanos en la época colonial en el caso del personaje de Rodas, y la fatalidad de ser mujer, en el caso de Hernández, hacen que los personajes vuelvan a esa tradición. En los dos relatos se hace una revisión de la historia de las mujeres en cuanto a sus derechos dentro del espacio privado. ${ }^{12}$ En ninguno de los dos cuentos la figura masculina es central. Se focaliza la acción en el retorno a ese referente histórico, donde se encuentran los orígenes. Si para el personaje de Rodas es necesario ir al pasado, atravesar el tiempo, para encontrar un goce en el amor cortesano, para el personaje de Hernández la reclusión y la vida conventual, se convierten en "lenguas siniestras e inevitables". De uno a otro cuento son evidentes las intertextualidades con la historia de la monja mexicana, pero se retrabaja desde una perspectiva que va variando de uno a otro personaje, como parte de los derechos que las mujeres lograrían durante los acuerdos de paz después de 1996. En "Lilith" relato de Ana

12 Claudia García comenta en su estudio sobre narradoras guatemaltecas de la posmodernidad que observa más bien una perspectiva situada en lo femenino (la circunstancia mujer) más que en lo político, con lo cual coincidiríamos en este análisis. Claudia García."Y mis pechos se irguieron en lo oscuro. Política y género en el cuento escrito por mujer en Guatemala (1987-2001). 13. http://lehman.cuny.edu/ciberletras/v18/garcia.html. 
María Rodas, su personaje que es homosexual va a suicidarse por haber sido abandonado por su pareja y acierta a ver la presencia de la muerte, antes de que ésta acontezca. Su personaje es dentro de la historia de la guerra un condenado por la xenofobia tanto del estado que no le reconoce derechos, como por la sociedad guatemalteca que ve su definición sexual como una enfermedad. Su final será la muerte. En tanto que en un cuento de Gloria Hernández, que fuera publicado en $1998^{13}$ o sea 8 años después de que apareciera el de Ana María Rodas, y ya dentro del espacio de la postguerra, el tema de la homosexualidad femenina está tratado desde otra perspectiva. El personaje femenino que se sabe homosexual ha perdido a su pareja y se duele por esta pérdida. En realidad el texto de Gloria Hernández maneja cierta ambigüedad y podríamos hacer una lectura sicoanalítica que nos diera otros resultados; sin embargo nos interesa señalar que este personaje dilucida su sexualidad de distinta manera que el homosexual en el caso de Rodas. En ambos relatos, los personajes no se encuentran en estados de mejoramiento, sino que dejan testimonio de las dificultades de concretar una relación no heterosexual, en el contexto moderno de la cultura de la guerra y de inicios de la postguerra. En Mal de ojo ${ }^{14}$ de Patricia Cortez, los personajes son hombres o mujeres que se encuentran en estados de precariedad, pero no solo económica, sino también sicológica. El lector se encuentra con una gama de personajes perdidos en medio de un tiempo que no alcanzan a entender. La mayoría de ellos sufren una especie de paranoia que no les permite vivir, digamos de forma normal, en espacios urbanos, muy periféricos, que han heredado como único hogar. "Páginas amarillas", es uno de estos ejemplos, el personaje gasta lo último que le queda de dinero en un

13 Gloria Hernández."Amante”. Desde la casa del cuento. Patricia Cortez,Gloria Hernández Montes, Carlos Nájera, Ligia Rubio-White y Gustavo Sánchez. (Guatemala: Editorial Cultura, 1998), 39-40.

14 El libro de Patricia Cortez se encuentra pendiente de publicación en la Editorial Cultura. 
libro con teléfonos y direcciones locales sin tener teléfono, y además cree que realmente le responden. El texto discute el caos cultural de un individuo que ha perdido la razón y que solo acierta a encontrar formas de sobrevivir practicando los vicios de la postmodernidad, como el hiper deseo social de la comunicación telefónica. El tema de la comunicación compulsiva y su ausencia por mala situación económica es un tema que esta escritora trabaja en varios relatos de su primer libro de cuentos, pero se aborda dentro de la discusión sobre los diversos niveles de locura. Los personajes están viviendo vidas extrañas, matizadas por aspectos mágicos, en los que creen. Saben que deben ir cubiertos por hierbas y objetos de protección como en "Mal karma”. Cortez está tratando un tema de principio de siglo XX, que se convierte para sus personajes de postguerra en formas de comprensión de la realidad histórica en que se encuentran inmersos. Cuando trabaja con personajes femeninos, el asunto no cambia, estas mujeres están representadas también dentro de la precariedad de la vida postmoderna, en espacios muy periféricos y en una posición absoluta de subordinación social. Algunos de sus personajes femeninos están enloquecidos por la magia o sumidos en los sistemas patriarcales, mostrando al lector, que se trata de sujetos femeninos que no han accedido a los cambios, por diversas razones. En "Nacimientos" se cuenta irónicamente la historia de una madre, cuyo marido desea un hijo varón; en esa búsqueda tiene amantes y desprecia a sus hijas mujeres y a su esposa. Al final logra tener lo que desea, su esposa queda esperando un niño, que dentro de la ironía y el sarcasmo del relato resulta ser de otro hombre. Al final, contrario a lo que sería el triunfo privado de lo femenino, el hombre no se queda a vivir con esta mujer, sino que la abandona. La maternidad está tratada de una forma totalmente desalmada, porque constituye para sus personajes un eslabón de la cadena de subordinación al sistema patriarcal. Uno de los textos que discute muy bien esta posición y representación de lo femenino subordinado a lo 
masculino es el relato titulado: "Si quisieras podrías esconder las nubes entre tu falda", en donde la narradora resulta ser una niña de nueve años que terminará siendo con el tiempo, la mujer del novio de Rosaura, su supuesta prima mayor, que al final en lo intrincado del relato es su verdadera madre. Las mujeres de sus historias resultan estar en estados decadentes, no importando que posean juventud. Están como imposibilitadas para cambiar de destino. Y no trabaja con finales felices o al menos alternativos para la vida de estos personajes. Las historias contadas por Cortez inducen a pensar a quien escribe este trabajo, que se discute el fracaso a nivel social e histórico, ya que las bases, la masa popular que ha participado de los movimientos políticos a nivel de partidos, o dentro de los esquemas de los sindicatos, propiciados por la democracia que los personajes representan, se encuentra perdida, acosada por la locura de un tiempo sin retorno, y sin visos de cambiar de situación histórica.

Los temas trabajados por estas escritoras están íntimamente relacionados con las imágenes que encontramos en las artistas del objeto, la instalación, la fotografía y el performance. Jessica Lagunas está creando imágenes superpuestas, que posibilitan otras imágenes mucho más grotescas ${ }^{15}$ en donde las texturas se entremezclan para crear imágenes surreales. Pareciera que sus personajes sufrieran una metamorfosis o el traslapamiento con otros yos. En su obra imaginativa hay crítica mordaz al matrimonio como institución que atrapa a la mujer en el espacio privado ${ }^{16}$ y también en el público. ${ }^{17}$ Sus objetos artísticos suelen tener relaciones directas con los mundos privados de la mujer, con esos espacios de

15 Jessica Lagunas. Diario intimo (2001). Composición digital con video.

16 Jessica Lagunas. "Ella de él” (1999). Instalación, Galería Velia de Vico.

17 Jessica Lagunas "La sombra" (1999). Instalación de zapatos de tacón sobre plancha de cemento de $4 \times 4$ metros. 
subordinado control femenino, objetos, espacios y tiempos de la mujer, que son intervenidos por su ojo acucioso en busca de deconstruir y emplazar conductas sistematizadas por el orden patriarcal.

Por otro lado el trabajo de Mariadela Díaz en relación con las escritoras establece importantes relaciones intertextuales dentro del mundo de la mujer. Uno de sus primeros trabajos constituía una pieza compuesta por pechos femeninos, los cuales podían ser pinchados por la concurrencia a cambio de obtener poesía por un pago de diez centavos, ${ }^{18}$ y aunque su primera intención no era la de criticar el procedimiento, ${ }^{19}$ la audiencia accedía a picar los pezones y obtener el poema por un pago mínimo. En nuestra lectura de este objeto creado por Díaz, la pieza establece las relaciones directas con el libro de la Memoria histórica, en cuanto a los métodos que el ejército y la policía desarrollaron sobre las mujeres durante la época de la guerra. La desaparición y el secuestro de mujeres durante los largos años de la guerra y aún en la postguerra, son imágenes sedimentadas en los imaginarios femeninos, que causan una especie de terror que se extiende a otros sectores de su práctica de la ciudadanía, provocando inclusive el olvido. Otro de sus trabajos que aparece en el año 2000 y que discute asuntos relacionados con la bisexualidad, la apariencia femenina, etc., se titula: "Bocetos primeras impresiones"; ${ }^{20}$ se trata de un collage en donde aparecen imágenes con connotaciones 18 Mariadela Díaz. "10 centavos, Poesía salida del pecho”. Instalación interactiva. ( i ) Guatemala.

19 De acuerdo con Mariadela Díaz creo unos pezones en una tabla de madera con hoyitos forrada con papel tapiz. El público en la actividad artística podía pinchar los pezones en el centro y sacar un papelito de adentro que contenía una palabra clave acerca de los poemas. En una mesa tenía varios poemas clasificados por temas, todos los poemas eran de mujeres guatemaltecas. En sí su intención fue crear un juego de azar. Aida Toledo, mensaje electrónico de Mariadela Díaz. Febrero 3, 2008.

20 Mariadela Díaz. "Bocetos Primeras Impresiones" (2000) Collage, Museo de Arte Mo- 
bisexuales. Esta generación de artistas y escritoras trae este tema a la mesa de discusión, y en función de las relaciones de este trabajo, establece relaciones intertextuales con algunos de los textos de Rodas, de M. Hernández o Gloria Hernández.

Dentro del mismo espacio cronológico, Andrea Aragón ha tomado fotos muy interesantes donde da cuenta de las imágenes femeninas de la postguerra, estableciendo diálogos con el tratamiento de la prostitución de la mujer postmoderna en los cuentos de Rodas y Cortez. Algunas de estas imágenes están tomadas en un famoso barrio llamado "La línea" en la zona 1 de la ciudad capital, donde antiguamente cruzaba el tren y que ahora se conoce como el sitio donde se encuentra la prostitución más barata de Guatemala. ${ }^{21}$ Las imágenes que nos da Aragón nos hablan de un sujeto social que no tiene salidas en la postguerra. Al mismo tiempo algunas otras de sus fotos muestran el acelerado proceso de globalización en que se debaten los sujetos mayas, en este caso femeninos, en una neo transculturación con la aldea global. ${ }^{22}$ Las fotos que observamos con el tema maya, encierran varias metáforas de la postguerra. Estos sujetos femeninos, ya no son ese género etnia que Gladis Bailey mencionaba en su artículo de hace casi 20 años ${ }^{23}$ se trata del resultado de un proceso acelerado de transculturación en cuyas

derno, Guatemala. http://www.rj-studio.com/mariadiaz/bocetos.htm

21 Andrea Aragón. Anti Postcards from Guatemala. "Prostitutes of La Línea"(2001). Guatemala. http://www.pixelpress.org/contents/antipost/girls.html

22 Andrea Aragón. Imaginingourselves. http://imaginingourselves.imow.org/pb/Story. aspx? G=1\&C=0\&id=1606\&lang=1. Ver también: Julia Ardón. Mujeres Mayas. http://juliaardon.blogspot.com/2008/01/mujeres-mayas.html

23 El carácter relacional de la categoría 'género' permite vincular las esferas pública y privada, explicar la persistente desigualdad social y la inequitativa distribución de poder y autoridad entre hombres y mujeres; la categoría etnia también remite a relaciones sociales cuya base es la diferencia cultural que históricamente ha implicado relaciones de poder, constituyéndose culturas dominantes y subordinadas. Ana Silvia Monzón. La diversidad es riqueza. Las rela- 
fotos observamos gran colorido, y cierta esperanza en los juegos que las muchachas mayas realizan. Aragón refleja diversas realidades salidas de un país pluricultural como el nuestro. Por un lado el encierro de las fotos de las prostitutas y del muchacho/a que huele pegamento, ${ }^{24}$ y luego el de las muchachas mayas, como en una especie de reflexión sobre la globalización, en cuanto a los estragos de la guerra y sus resultados -digamos positivos o ascépticos-- en la postguerra.

Carolina Pineda se une a este grupo de artistas en cuanto a la temática del cuerpo, y la violencia y atropello que sufre el cuerpo mancillado de la postguerra. Mantiene, nos parece, una estética mucho más ligada al emplazamiento de la censura, y va discutiendo los distintos niveles que ésta alcanza en relación con temas que son aún un tabú para las antiguas y nuevas generaciones, que se caracterizan por un retorno a los esencialismos religiosos. Uno de sus objetos, en los que se mezcla texto escrito con imagen se trata de un poster, donde una pieza interior con zipper en el frente ha sido colocada sobre lo amplio de la página. Quien observa debe abrir el zipper y encontrará un texto corto y punzante como en el estilo del epigrama, relacionado con la discusión actual sobre el sida, la repetición de la palabra en el texto acusa mucho más el sentido. La imagen de por sí grotesca le propone a la audiencia atreverse a abrir un zipper que conlleva connotaciones de distinto tipo sexual, pero es la única opción para leer el texto. Su objetivo estaba directamente vinculado con los atropellos públicos y privados sobre los homosexuales y las minorías. El trabajo de esta artista está provisto de un

ciones de género en sociedades pluriculturales, 8. http://www.generoyambiente.org/admin/admin_biblioteca/documentos/diveridad\%20riqueza. pdf

24 Andrea Aragón. Anti Postcards from Guatemala. "Kid in downtown streets". (2001. Guatemala. http://www.pixelpress.org/contents/antipost/drugs.html 
tono un tanto carnavalesco. ${ }^{25}$ Se discute en algunas piezas el tema de la relación desigual de pareja, que termina siendo subvertida por el sujeto o cuerpo femenino en un desplazamiento de identidades múltiples como en uno de sus objetos de arte, en el que se escribe un texto en letras rojas sobre la radiografía real de un enamorado/a. El texto discute en forma fragmentada la imposibilidad de la relación, pero también alude a la posibilidad de poder ver el interior de una relación amorosa únicamente con los rayos $\mathrm{x} .{ }^{26} \mathrm{El}$ cuestionamiento al escepticismo amoroso de postguerra es muy interesante en el trabajo de esta artista. En cierta forma los personajes de las narradoras son también escépticos, como en el caso de los relatos de Rodas; por ejemplo en "Abril de noche", donde el personaje femenino le hace creer al marido que sí, que lo ha engañado con otro, solo para poder deshacerse de una relación en la cual, ese otro que la emplaza, efectivamente le es infiel en todos los niveles de la relación de pareja. Esta misma artista ha intervenido un libro que estaba siendo utilizado por la Oficina de los Derechos de la Mujer y le ha titulado:"Intervención inconclusa", y desde ese momento o etapa de la intervención se produce la ironía como figura retórica, para reclamar y discutir lo contradictorio del uso del libro. Desde la portada el libro aparece intervenido por una foto de la artista de esas que se estilan dentro de una especie de camafeo. La imagen es la de una mujer sobre una motocicleta, en traje negro y semidesnuda. El libro se constituye en una especie de manual que habla sobre los derechos de las mujeres, no importando su situación económica, y a cada lectura, Pineda le añade imágenes cuestionadoras y emplazantes, resueltas en fotos, dibujos de la artista en acuarela y otras técnicas, textos que emplazan lo dicho por el libro,

25 Usamos este término para definir lo que para Mihail Bajtin es el mundo al revés, o sea el proponer la inversión de los roles, situaciones e inclusive ropas, que aluden todos al imaginario cultural.

26 Aida Toledo. "En el performance y la instalación: espacios imaginarios de artistas guatemaltecas". Isis Internacional (Santiago de Chile) Ediciones de las mujeres n. 33, (2002):154. 
por constituir pura teoría, por no tener conecciones con la realidad del mundo de la mujer guatemalteca, falto totalmente de derechos, tanto en el espacio privado como público. Los mundos de Carolina Pineda aparecen ante el público provenientes de un mundo tortuoso, en los que el sujeto femenino es híbrido, producto de la realidad de la postguerra. El tratamiento de los abusos sobre las minorías, sobre todo sobre los homosexuales, lesbianas y mujeres en general, son tratados crudamente por Carolina sin concesiones.

Como una conclusión podríamos decir que las narradoras del relato corto a quienes nos hemos referido, manejan y trabajan temas, problemáticas sociales y políticas enquistadas en los imaginarios guatemaltecos a lo largo de muchos años de represión, entre los que se cuentan los años de la guerra de contrainsurgencia. Las formas que asumen sus textos las descartan en la mayoría de las ocasiones de las antologías de narrativa corta, precisamente, y como una contradicción, por la extensión y condensación de las historias, que suelen venir matizadas con mezclas con otros géneros como la poesía conversacional, el teatro experimental, la leyenda, los cuentos de hadas, de niños, etc. En cuanto a los efectos sicológicos de la postguerra que se hacen evidentes en sus obras, el lector observa que sus textualidades suelen preferir el tratamiento de la sexualidad como maneras de atacar al sistema y denunciar los abusos de los que de manera colectiva han sido objeto como mujeres. Y es obvio que arremeten contra la censura que se ha recrudecido en los últimos años, apoyada tanto por religión, la educación secundaria y universitaria. El trabajo de estas artistas fue llamado en los primeros años de la postguerra como "jueguitos vanguardistas" sobre todo por quienes se sentían lastimados y acosados por sus representaciones efímeras de toque kitsch; de cierta forma su aparición en la escena artística se constituyó en un cambio de registro mucho más popular a nivel social. El arte durante la época de la guerra, siguió su decurso y desarrolló hacia nuevas formas que 
determinaron la aparición de los happenings postmodernos, las instalaciones y los arte-objetos, estética a la que pertenecen las artistas mencionadas en este trabajo. Tanto escritura como imagen visual o plástica, se transforman en formas de catarsis colectiva para una población sometida a largos años de violencia. Unas y otras imágenes parecen salidas de situaciones similares. Son oníricas por un lado, pero por otro, acusan un nuevo realismo naturalista, ya que han heredado en los imaginarios colectivos el miedo a la muerte, la tortura o el sacrificio a que fueron sometidos sus contemporáneos, en el río revuelto de la guerra de contrainsurgencia. ${ }^{27}$ Tanto parodia como ironía aparecen en forma constante en sus obras; estos elementos han sido identificados como posmodernos y se transforman en aspectos que caracterizan a la postguerra, funcionan para dejar testimonio de la crudeza de la guerra y hacer énfasis en el papel jugado, voluntaria o involuntariamente por la mujer guatemalteca.

* Profesora Asociada. Modern Languages and Classics. Universidad de Alabama. 315 C Cedar Crest Sq./Tuscaloosa, AL 35401. Tel. 205-792-1291. aidatoledo@bama.ua.edu/porlosbordes2003@yahoo.com

27 En la violencia que llegó a su apogeo en 1982, el número de mujeres asesinadas y abusadas alcanzó su máximo nivel. En 1981 y 1982, el periodo de la contrainsurgencia se caracterizó por asesinatos masivos en el área rural, la proporción de mujeres entre todas las víctimas identificadas llegó al 21 por ciento, su máxima desde la expansión del conflicto en los sesenta. Para todo el conflicto armado, las mujeres representaban el 15 por ciento de muertos identificados en la base de datos. Violencia institucional en Guatemala, 1060 a 1996: una reflexión cuantitativa, 103-104. http://shr.aaas.org/guatemala/ciidh/qr/spanish/sp qr.pdf 